\title{
Seasonal Extreme Rainfall Over Indian Monsoon Region: A Moisture Budget Analysis to Distinguish the Role of ENSO and non-ENSO Forcing
}

\section{Ashish R Dhakate}

Indian Institute of Tropical Meteorology

Prasanth A. Pillai ( $\sim$ prasanth@tropmet.res.in )

Indian Institute of Tropical Meteorology https://orcid.org/0000-0002-8159-6066

\section{Research Article}

Keywords: Flood and drought, Indian summer monsoon rainfall, ENSO, IOD, EQWIN, moisture budget, MSE budget

Posted Date: November 2nd, 2021

DOI: https://doi.org/10.21203/rs.3.rs-1035899/v1

License: (c) (i) This work is licensed under a Creative Commons Attribution 4.0 International License.

Read Full License

Version of Record: A version of this preprint was published at Theoretical and Applied Climatology on March 23rd, 2022. See the published version at https://doi.org/10.1007/s00704-022-04016-5. 
1 Seasonal extreme rainfall over Indian monsoon region: A moisture budget analysis to distinguish the role of ENSO and non-ENSO forcing

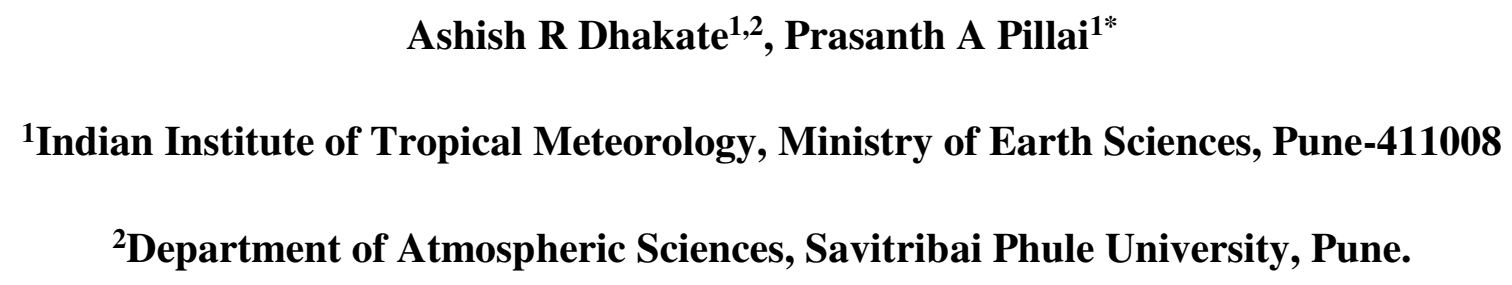

*Corresponding Author

Prasanth A Pillai

Monsoon Mission Program,

Indian Institute of Tropical Meteorology,

Ministry of Earth Sciences, Pune-411008.

Emai:prasanth@tropmet.res.in

Orchid id:0000-0002-8159-6066 


\section{Abstract}

Indian summer monsoon rainfall (ISMR) variability of $\pm 10 \%$ of its long-term mean leads to flood and drought, affecting the life and economic situation of the country. It is already established that the interannual variability of ISMR is influenced by large scale boundary forcing such as SST anomalies of tropical Pacific, Indian and Atlantic Oceans. The ISMR association between Pacific SST anomalies in the form of El Nino Southern Oscillation (ENSO) is only studied in detail. Meanwhile, the present and previous studies show that the ENSO accounts for around 50\% of the extreme years, while the other half is associated with other processes. A differentiation between extremes induced by ENSO and non-ENSO processes are attempted here with the help of moisture and moist static energy budget. The significant contribution to the rainfall extremes comes from moisture advection induced by anomalous winds generated by the boundary forcing and the secondary contribution from moisture convergence. For the non-ENSO cases, there is a contribution from local fluxes, which are not prominent in the cases of ENSO induced cases. In the ENSO cases, anomalous winds are from the equatorial central Pacific, while EQWIN/IOD cases influence extremes through the local evaporation and moisture advection from the Indian Ocean. Extreme years independent of ENSO/IOD/ EQWIN have moisture advection from the anomalous winds across Africa and the Atlantic and are associated with moisture advection toward the northern parts of India. These differences in moisture processes are responsible for the difference in rainfall distribution over India also.

Keywords: Flood and drought, Indian summer monsoon rainfall, ENSO, IOD, EQWIN, moisture budget, MSE budget 
The seasonal rainfall (June to September, JJAS) receiving over India, called Indian summer monsoon rainfall (ISMR), accounts for 70-80\% of the annual rainfall over India. The ISMR has a seasonal mean of $84 \mathrm{~cm}$ with a coefficient of variability of less than $10 \%$. Still, the variability of the ISMR to a flood (above average) or drought (below normal) is crucial for the Indian economy, which depends on rain-fed agriculture for the life of millions of its population. Variations in the monsoon rainfall affect India's total food grain yield and the country's economy, which largely depends on agriculture (Krishna Kumar et al. 2004). These extremes cause a million dollars of damage to the country's economy as the rainfall variability is directly related to crop yield and food production ( Gadgil et al., 2006). Even a modest decrease of $10 \%$ of the long term mean rainfall leads to a significant reduction in rice production over India (Swaminathan 1987; Abrol and Gadgil 1999). In addition, the interannual variability of ISMR shows a more substantial impact on the gross domestic product (GDP) and agricultural production of the country (Gadgil 1996; Webster et al. 1998). Thus, a better knowledge of the mechanism of different causes of these extremes is needed, leading to better prediction of them.

Earlier studies identified that interannual variability of ISMR is mainly controlled by slow varying factors such as sea surface temperature (SST), snow cover and sea ice extent etc. (Charney and Shukla 1981). In these boundary forcing, ISMR association with the SST anomalies of tropical east Pacific (El Nino- Southern Oscillation, ENSO, Walker 1924, Rasmussen and Carpenter 1983) and Indian Ocean (Indian Ocean Dipole, IOD, Saji et al. 1999, Webster et al. 1999) are well known for past 3-4 decades. The ENSO influences ISMR through modifications of east-west Walker circulation, while the IOD influence is through the modification of local Hadley circulation over the Indian Ocean. An El Niño event leads to anomalously low ISMR through the associated Southern Oscillation, suppressing convection over the Indian subcontinent, and vice versa for La Niña. By contrast, a positive IOD, when free of an El Niño's influence, induces atmospheric circulation anomalies, resulting in anomalously high ISMR. In particular, the cold anomalies in the eastern Indian Ocean are conducive to vapour transport by generating anomalous meridional circulation. Meanwhile, these boundary forces such as ENSO-IOD etc. are related to each other and influence the ISMR independently. Thus how these boundary forces contribute to ISMR separately and in combination is not clear yet. Annamalai and Liu (2005) noted that regional SST anomalies influence the magnitudes of monsoon-related rainfall and circulation anomalies. Gadgil et. al. 

(2004) showed that the extremes of ISMR are related to the equatorial Indian Ocean in the form of EQUINOO. Many studies such as Rajeevan and Sridhar(2008); Yadav( 2017), etc. indicated that the SST anomalies in the Atlantic Ocean can also influence the ISMR on the interannual time scale. Even though these boundary forcing influencing monsoon are recognised by many studies, the mechanism of their interaction with the extreme rainfall is not studied in detail.

Table 1 below shows the years of positive and negative seasonal monsoon years $(+/-$ $10 \%$ of LPA, long-period average) based on Indian summer monsoon rainfall (land-point average rainfall for Indian region from India meteorological Department, IMD) during the 1950-2020 period. Severe monsoons are based on threshold cutoffs of +- 10\% LPA for the climatology period 1950-2020. The deficit (drought) monsoon of 2014 accounted for 90\% and 1972 recording $77 \%$ rain of LPA. Similarly, the flood year of 1956 received $110 \%$ of LPA with 1988 recording $120 \%$ of the long period average. The extreme years are again divided based on their co-occurrence with other SST forcing such as ENSO, IOD, etc. The table clearly shows that only around $50 \%$ of the severe years are associated with El Nino/La Nina. Thus, it is clear that some other factors are responsible for severe monsoon. Many factors such as IOD, EQWIN, Atlantic ocean SST, etc can contribute to the extreme monsoon years (Rajeevan 2008, Ajaymohan and Rao 2008, Gadgil et.al 2004). The role of ENSO in modulating the ISMR is studied in detail (Webster and Yang 1992, Webster et al. 1998, Chung et.al. 1999, Pillai and Annamalai 2012 and many other studies) and the interaction is explained well (Pillai and Annamalai, 2012 etc). Meanwhile, the interaction with other boundary forcing is not studied in detail. The mechanism is not explained mainly due to the fewer co-occurrence with ISMR and their interrelationship with ENSO. Here in the present study, we try to differentiate the extreme monsoon years for ENSO and non-ENSO years and the mechanism leading to extremes based on moisture and moist static energy budget. An early study by Pillai and Annamalai (2012) used the same budget analysis to understand the mechanism associated with severe monsoons (>1.5 standard deviations) and the majority of these years were associated with ENSO. In this study, we are looking at whether there is any difference between the moisture mechanism for ENSO and non-ENSO extreme rainfall and how other boundary forces such as Indian Ocean processes contribute to observed ISMR extremes.

\section{Data and Methodology}


The present study uses long term data of Indian summer monsoon rainfall (ISMR) obtained from the gridded data of IMD (Pai et al 2014) for 1950-2020. Severe monsoons are based on +- 10\% LPA threshold cutoffs for long term (1950-2020) climatology. Sea surface temperature from the Hadley Centre (HadISST, Rayner et al., 2003) is also used for the same period. Moisture and moist static energy budget analysis are performed using threedimensional wind data, specific humidity and temperature from surface to $100 \mathrm{hPa}$ along with surface temperature, pressure, sensible and latent heat flux and radiation fluxes at the surface and top of the atmosphere from the NCEP reanalysis (Kalney, et.al 1996). Moisture and moist static energy budget analysis are performed similar to Su and Neelin (2002), Pillai and Annamalai (2012) and the equations are summarised below.

$\partial_{t}\langle T\rangle^{\prime}+\left\langle D_{T} T\right\rangle^{\prime}+\left\langle\omega \partial_{p} s\right\rangle^{\prime}=\left\langle Q_{c}\right\rangle^{\prime}+\frac{g}{P_{T}}\left(F^{\prime}{ }_{\text {rad }}+H^{\prime}\right) \ldots \ldots$ equ $(1)$

$\partial_{t}\langle q\rangle^{\prime}+\left\langle D_{T} q\right\rangle^{\prime}+\left\langle\omega \partial_{p} q\right\rangle^{\prime}=\left\langle Q_{q}\right\rangle^{y}+\frac{g}{P_{T}}\left(E^{\prime}\right) \ldots \ldots$ equ $(2)$

$D_{T}=D_{q}=V \cdot \nabla-K_{H} \nabla^{2} \ldots \ldots$ equ $(3)$

$\left\langle\omega \partial_{p} h\right\rangle^{\prime}=-\left\langle D_{T} T\right\rangle^{\prime}-\left\langle D_{q} q\right\rangle^{\prime}+\frac{g}{P_{T}}\left(F^{\prime}{ }_{r a d}+H^{\prime}+E^{\prime}\right) \ldots e q u(4)$

We can calculate the moisture equation for rainfall based on equation 2 and the MSE budget can be calculated from equation 4. Meanwhile, the moisture advection term can be split into the contribution from the mean and anomaly of wind and moisture in equation 5 below.

$\left\langle V \cdot \nabla q^{\prime}\right\rangle=\left\langle V^{e} \cdot \nabla q^{\prime}\right\rangle+\left\langle V^{\prime} \cdot \nabla q^{c}\right\rangle+\left\langle V^{\prime} \cdot \nabla q^{\prime}\right\rangle+\left\langle\overline{V^{n} \cdot \nabla q^{n}}\right\rangle \ldots e q u(5)$

Standardised anomalies of JJAS season above (below) \pm 1 SD are chosen to represent the positive and negative years of ENSO, IOD and EQUINOO. Niño 3.4 is calculated over the region (5N-5S, 170W-120W, Trenberth,1997). Values more than +1 SD are termed as El Nino and those below -1 SD are referred to as La Nina events. The intensity of the IOD is represented by anomalous SST gradient between the western equatorial Indian Ocean (50E$70 \mathrm{E}$ and $10 \mathrm{~S}-10 \mathrm{~N})$ and the southeastern equatorial Indian Ocean (90E-110E and 10S-0N). This gradient is named as Dipole Mode Index (DMI). When the DMI is positive then, the phenomenon is referred to as the positive IOD and when it is negative, it is referred to as negative IOD (Saji et. al., 1999). EQWIN index is the negative of the anomaly of the zonal component of the surface wind at the equator $\left(60^{\circ} \mathrm{E}-90^{\circ} \mathrm{E}, 2.5^{\circ} \mathrm{S}-2.5^{\circ} \mathrm{N}\right)$ normalized by its 
147 standard deviation (Gadgil et. al., 2004). Easterly wind anomaly is treated as positive 148 EQWIN and vice versa.

Composite of anomalies of rainfall, SST, wind, SLP etc of strong and weak monsoon years with different combinations (co-occurring) with ENSO, IOD, EQWIN are carried out.

151 The moisture and MSE analysis are performed separately for all these co-occurrence years in composite to understand the similarities and differences of these different processes which can contribute to monsoon extremes. Extremes independent of all these are also treated separately to interpret the possible mechanism.

155

\section{RESULTS}

\section{a) Rainfall distribution of excess years associated with different boundary forcing.}

Figure 1 shows the spatial distribution of rainfall for excess rainfall year composite from all the boundary forcing based on Table 1 . The La Nina co-occurred positive rainfall anomalies spread all over the Indian land region with a maximum over the southern and western part of the Indian land region. At the same time, the non-ENSO cases have stronger rainfall over the central monsoon core region in association with positive IOD and south-western parts of India for the third independent category. For the drought cases, weak ISMR anomalies are distributed over the entire monsoon region. The rainfall anomalies are mainly concentrated over the north-eastern part of India and western cost for negative eqwin and are over northwestern India for the independent case. Thus, both figure 1 and table 1 indicate strong variation in intensity and distribution of extreme rainfall in the presence of different boundary forcing. It will be interesting to analyse whether the difference in spatial distribution is also the result of large scale circulation features associated with different types of boundary forcing.

\section{b) Anomalous large scale features associated with seasonal extremes}

Figure 2 shows the large scale SST and circulation features of different categories of flood and drought years.Sea level pressure (SLP) anomalies and upper-level velocity potential (VP) for the same are shown in figure 3. During the La Nina years (fig 2a), the SST is anomalously cool in the equatorial east Pacific with strong easterly wind anomalies in the Indian land region. There is reduced SLP and increased convergence over the Indian land region (fig 3a), with the opposite pattern observed over the tropical east and central Pacific regions (Fig 2a). This indicates that the divergence aids the strong ascent over the monsoon region. Strong 
easterly flow from the central Pacific to the monsoon region is associated with the occurrence of La Nina in the Pacific. Meanwhile, for the non-La Nina cases, there are no strong SST anomalies in the tropics. It has a stronger dipole structure and cross-equatorial flow for positive IOD case and has stronger winds over AS and African region for the third category (Fig $2 \mathrm{~b}$ and c). The SLP and divergence centre differences are between the west and east Indian Ocean for the IOD case and between the Indian region and the Atlantic for the third category(Figure $3 \mathrm{~b}$ and $\mathrm{c}$ ). Thus the local circulation (i.e., south-westerly flow from the Indian ocean to monsoon region is stronger in the case of non-ENSO extremes, while the easterly flow from the equatorial central Pacific is stronger for La Nina co-occurred flood years.

Meanwhile, for drought cases, there is an easterly wind anomaly to the Indian Ocean from the Indian land region induced by the strong divergence over the monsoon region. There is additional flow from India and Bay of Bengal $(\mathrm{BoB})$ to equatorial central Pacific for ENSO cases (Fig2 d), while the easterly over the Indian region converge to the central Indian Ocean during negative EQWIN years and it flows to the African area for the third category (Fig 2f). Thus the easterly flow to the Indian Ocean is common in all drought cases.

\section{c) Moisture and MSE budget}

Moisture and MSE budget as performed by earlier studies such as (Pillai and Annamalai 2012 etc ) will help us find out the different roles of moisture, fluxes etc in the formation of the extremes under the influence of different categories of external forcing.

1) Budget analysis for severe flood years

Figure 4 shows the moisture budget as per equation 2 above for the flood years of different categories. For La Nina composites, the increased rainfall over the Indian land region is balanced by moisture advection and moisture convergence, while the evaporation is anomalously weak and is in the opposite phase (Fig 4 a,b,c). In comparison with the wind structure, we can interpret that the wind from the Pacific induced by La Nina may be the reason for anomalous moisture advection over the monsoon region. Similarly, for the MSE budget, the significant contribution is from moisture advection and a weaker contribution from net fluxes (not shown). Temperature and sensible heat play a very minute role in the increased rainfall over the Indian land region. Meanwhile, in the non-ENSO cases associated with positive IOD, moisture convergence and moisture advection along with evaporation play a major role in increased rainfall, while MSE convergence is by moisture advection (Fig 4 e- 
h). In the other independent category, there is moisture convergence over India and the equatorial African region, with increased moisture convergence and increased local evaporation over the Indian Ocean and Indian land region (Fig 4 i-1). MSE convergence is contributed by moisture and temperature advection, while the contribution from net heat flux and SHF is balanced. In both these non-ENSO induced cases, wind anomalies are more robust over the Indian ocean region and they got converged in the north-eastern part of India, coinciding with increased moisture advection, while the convergence over southern parts has coincided with increased local evaporation processes.

2) Budget analysis for drought years

Figure 5 shows the budget for drought years with and without El Nino co-occurrence. El Nino co-occurrence years have decreased rainfall over the monsoon region balanced by the moisture divergence there aided by dry air advection due to moisture transport to the western Indian Ocean and equatorial Pacific (Fig 5 a-d). Evaporation also favours drought over the monsoon region. MSE divergence is also contributed mainly by dry air advection and temperature advection. Net radiation also contributed to decreased MSE, while SHF contribution is the opposite (not shown). Meanwhile, for non-ENSO cases, reduced rainfall is mainly balanced by moisture divergence. At the same time, the dry air advection is stronger over the north-central Indian region, and there is evaporation contributing to the rainfall budget in the southern part of India. For the MSE budget, temperature advection is also contributing. The non-ENSO cases are further split into the contribution from negative EQWIN and cases independent of ENSO and IOD. In the case of negative EQWIN, rainfall is mainly balanced by moisture divergence over the monsoon region, while MSE divergence is balanced by moisture advection (Fig 5 e-h). In independent cases, rainfall decreases are balanced by moisture divergence and dry air advection is in the northern part of India, while evaporation is important for southern regions (Fig 5 i-l). Moisture advection itself will contribute to MSE divergence also.

\section{d) Role of anomalous circulation in moisture advection}

The above analysis indicates that anomalous moisture advection is the major contributor to these composites' moisture and MSE budget. As per equation 5, anomalous moisture advection can be split into the contribution from the climatological and anomalous contributions of moisture and wind. Here in this section, we split the moisture advection by its components in the equation and explained the difference for different events. 
Figure 6 shows the components of the equation for flood years. In this first figure is the contribution from anomalous wind advecting on climatological moisture (term1, ADV1), second is the contribution by climatological moisture advected by climatological wind (term2, ADV2) and third is the contribution from anomalous moisture advected by anomalous wind (term3, ADV3). In the cases of flood introduced by La Nina in the Pacific, moisture advection by anomalous wind acting on climatological moisture is to western and northern parts of India (Fig6 a-c). In contrast, the climatological wind working on the anomalous wind will contribute to the southern part of India. In the north-eastern region, the major contribution is from the climatological moisture advected by the climatological wind. In the positive IOD case (Fig6 d-f), anomalous wind advect moisture to the north-eastern parts and there is dry air advection in the southern part of India. The second component also contributes to moisture advection in north-east India with weak positive advection in the southern peninsular region, while the advection contributed by anomalous terms have a negative contribution. Thus acting all these terms will result in increased moisture advection to the north and eastern part of India, with weak negative moisture advection to the southern region of the Indian subcontinent. In the third category of flood cases (Fig6 g-i), both the first and second component contributes to the total moisture advection. Thus in the case of La Nina induced flood, climatological moisture over the Indian region advected by anomalous wind contributes to moisture advection leading to moisture convergence and rainfall. During IOD years also, the anomalous wind is causing moisture advection to cause convergence. But in the third case anomalous advection by both anomalous wind and climatological wind contribute to moisture convergence.

The same components of anomalous advection for drought cases are provided in Figure 7. El Nino droughts have anomalous wind advecting climatological wind that causes dry air advection to the northern part of India, while the anomalous moisture advected by climatological wind induces dry advection to southern India and the BoB region (Fig 7 a-c). The anomalous wind causes moisture advection and convergence for negative EQUINOO cases (Fig7 d-f), while for the third category, anomalous wind acting on mean moisture causes dry air advection to the northern part of India, while that by the climatological wind causes that over the southern peninsular region (Fig7 g-h). These analyses indicate different wind structures and associated moisture processes, leading to anomalous convection induced by different boundary forcing over the monsoon region.

\section{Discussion and Conclusion.}


Indian summer monsoon seasonal extremes, which accounts for more than $10 \%$ variability of long-term mean, account for the flood/drought affecting the livelihood of millions of people in the subcontinent. Earlier studies on these extremes accounted for SST anomalies associated with El Nino Southern Oscillation (ENSO) as the major factors responsible for these extremes and explained the relationship between these two in detail. But it will account for half of the extremes in the last century and further studies conclude that other factors such as Indian Ocean Dipole, EQWIN, Atlantic SST, mid-latitude interactions etc can also account for extremes, but how these different mechanisms contribute to the extremes are not examined well. The preset study understands the moisture mechanism behind these different contributors of extreme ISMR.

The extremes induced by different boundary forcing have a difference in the spatial distribution of rainfall anomalies over the Indian land region. The La Nina co-occurred stronger rainfall anomalies spread all over the Indian land region with a maximum over the southern and western part of the Indian land region, while the non-ENSO cases have stronger rainfall over the central monsoon core region and south-western parts of India. Meanwhile, for the drought cases, weak ISMR anomalies are distributed over the entire monsoon region, while it is mainly concentrated over the north-eastern part of India and western cost for negative EQWIN and is over north-western India for the independent case.

The study points that the ENSO induced extremes have stronger wind patterns from the Pacific Ocean associated with convergence/divergence centres over India covering the Indian Ocean and the Pacific Ocean. The rainfall is mainly contributed by moisture advection and convergence process. The anomalous wind acting on climatological moisture is the major process in these remote influenced ISMR extremes. Meanwhile, in the case of non-ENSO cases induced severe monsoon, both mean and anomalous wind induces moisture advection to the monsoon region and also local evaporation plays a secondary role. Thus the mechanisms by which the rainfall anomalies are formed in these different cases are different.

The budget analysis also explains the difference in the distribution of rainfall anomalies during different cases. The difference in the area of extreme rainfall is in accordance with the wind anomalies and associated moisture transport and convergence. Thus, the study concludes that even though many external factors induce the extremes of ISMR, the mechanism behind each external factor is also different. Capturing these different mechanisms is needed for the better prediction of these different categories of extremes. 
308 Acknowledgements: Authors are thankful to Prof. Ravi S. Nanjundiah, Director, Indian 309 Institute of Tropical Meteorology (IITM) and Dr Suryachandra A Rao, Program manager, 310 Monsoon Mission, IITM for encouraging to carry out this research work. The IITM HPC 311 support is duly acknowledged. A. R Dhakate also acknowledges Savitribhai Pule University 312 Pune. The IITM is fully funded by the Ministry of Earth Sciences, Government of India. All 313 the figures are prepared using Ferret software freely available from 314 https://ferret.pmel.noaa.gov/Ferret/

315 Funding Information: Authors have no funding information

316 Data availability: All the data sets used are available online from NCEP (atmospheric variables) https://psl.noaa.gov/data/gridded/data.ncep.reanalysis.html., HadISST from https://www.metoffice.gov.uk/hadobs/hadisst/data/download.html and IMD rainfall from https://www.imdpune.gov.in/Clim_Pred_LRF_New/Grided_Data_Download.html. Proceessed data can be maid available on request.

\section{Competing Interests}

322 The authors declare no competing interests.

323

324

\section{Author's contrinution}

A. R Dhakate- Formal analysis, Conceptualization, Validation, Software, writing original draft. P.A Pillai- Cocneptulisation, supervision, methodology and validation., writingreviewing and editing.

\section{Code availability:}

Moisture and moist static energy budget calculation code can be made available on request.

\section{Ethics Decleration}

\section{Ethics Approval:}

Not applicable.

\section{Consent to participate:}

Not applicable 
Not applicable.

\section{Conflict of Interest}

The authors have no conflicts of interest to declare.

References:

Abrol Y.P., and Gadgil S., Eds., 1999: Rice- in a Variable Climate. APC Publications Pvt Ltd.

Ajayamohan R.S., Rao S. A., 2008: Indian Ocean dipole modulates the number of extreme rainfall events over India in a warming environment. Journal of the Meteorological Society of Japan Ser II 86:245-252 DOI: 10.2151/jmsj.86.245 .

Annamalai H., Liu Ping, and Xie Shang-Ping., 2005: Southwest Indian Ocean SST Variability: Its Local Effect and Remote Influence on Asian Monsoon. Journal of Climate, DOI: https://doi.org/10.1175/JCLI3533, pp. 4150-4167 .

347 Charney, J. G., and Shukla J., 1981: Predictability of monsoons. Monsoon Dynamics, J.

348 Lighthill and R. P. Pearce, Eds., Cambridge University Press, pp. 99-108

349 Chung, C., and Nigam S., 1999: Asian summer monsoon-ENSO feedback on the Cane350 Zebiak model ENSO. J. Climate, 12, 2787-2807.

351 Gadgil S., and Rupa Kumar K., 2006: The Asian Monsoon-Agriculture and economy. Book: The Asian Monsoon, Chapter 18, Ed. B. Wang, Springer, Berlin, Heidelberg, 2006.

Gadgil Sulochana., Vinayachandran P. N., Francis P. A., Gadgil Siddhartha., 2004: Extremes of the Indian summer monsoon rainfall, ENSO and equatorial Indian Ocean oscillation, Geophysical Research Letters, Vol. 31, L12213, doi:10.1029/2004GL019733.

Gadgil, S., 1996: Climate change and agriculture-An Indian perspective. Climate Variability and Agriculture, Book Eds. Y. P. Abrol, S. Gadgil, and G. B. Pant, Narosa Publications, pp. 358 1-18.

359 Krishna Kumar K., Rupa Kumar K., Ashrit R. G., Deshpande N. R., Hansen J. W. , 2004 : 360 Climate impacts on Indian agriculture. International Journal of Climatology, 24: pp. 1375 3611393, https://doi.org/10.1002/joc.1081.

362 Pai D.S., Latha Sridhar, Rajeevan M., Sreejith O.P., Satbhai N.S. and Mukhopadhyay B., 363 2014: Development of a new high spatial resolution $\left(0.25^{\circ} \mathrm{X} 0.25^{\circ}\right)$ Long period (1901-2010) 364 daily gridded rainfall data set over India and its comparison with existing data sets over the 365 
Pillai P., and Annamalai M., 2012: Moist Dynamics of Severe Monsoons over South Asia: Role of the Tropical SST, Journal Of The Atmospheric Sciences, Volume 69,pp. 97-115.

Rajeevan M., and Sridhar L., 2008: Inter-annual relationship between Atlantic sea surface temperature anomalies and Indian summer monsoon, Geophysical Research Letters, Vol. 35, L21704, doi:10.1029/2008GL036025.

Rajeevan M., Bhate Jyoti, and Jaswal A.K., 2008: Analysis of variability and trends of extreme rainfall events over India using 104 years of gridded daily rainfall data, Geophysical Research Letters, 35, L18707, doi:10.1029/2008GL035143.

Rasmussen E. M., and Carpenter T. H., 1983: The relationship between eastern equatorial Pacific sea surface temperature and rainfall over India and Sri Lanka. Mon. Wea. Rev., 111, pp. 517-528.

Rayner, N. A., Parker, D. E., Horton E. B., Folland C. K., Alexander L. V., Rowell, D. P., Kent, E. C., Kaplan, A.,2003: Global analyses of sea surface temperature, sea ice, and night marine air temperature since the late nineteenth century J. Geophys. Res.Vol. 108, No. D14, 4407 10.1029/2002JD002670

Saji, N. H., Goswami B. N., Vinayachandran P., and Yamagata T., 1999: A dipole mode in the tropical Indian Ocean. Nature, 401, pp. 360-363.

Su Hui and Neelin David J., 2002 Teleconnection Mechanisms for Tropical Pacific Descent Anomalies during El Niño, Journal of the Atmospheric Sciences, Volume 59,pp. 2694-2712.

Swaminathan, M. S.,1987: Abnormal monsoons and economic consequences: The Indian experiment. Monsoons, Book Eds. J. S. Fein and P. L. Stephens, Wiley and Sons, pp. 121134.

Trenberth Kevin E., 1997: The Definition of El Niño. BAMS, Vol 78, no.12, pp 2771-2777. doi.org/10.1175/1520-0477(1997)078<2771:TDOENO>2.0.CO;2

Walker G. T., 1924: Correlation in seasonal variations of weather. IV : A further study of world weather. Mem. Indian Meteorol. Dept, 24, pp. 275-332.

Webster Peter J., Moore Andrew M., Loschnigg Johannes P., Leben Robert R.; 1999: Coupled ocean-atmosphere dynamics in the Indian Ocean during 1997-98. Nature, volume 401, pp. v356-360 .

Webster P. J., Magana V.O., Palmer T. N., Shuka J., Tomas R. T.,. Yanai M, and Yasunari T., 1998: Monsoons: Processes, predictability and the prospects of prediction. J. Geophys. Res., 103(C7), 14, pp. 451-510.

Webster, P. J., and Yang S., 1992: Monsoon and ENSO: Selectively interactive systems. Quart. J. Roy. Meteor. Soc., 118,pp. 877-926. 
Webster, P. J., . Magaña V. O, T. N. Palmer, , J. Shukla, , R. A. Tomas, , M. Yanai, , and T. Yasunari, 1998: Monsoons: Processes, predictability, and the prospects for prediction. J. Geophys. Res., 103, 14 451-14 510.

Yadav R. K., 2017: On the relationship between east equatorial Atlantic SST and ISM through Eurasian wave. Cli. Dyn., 48, pp. 281-295.

\section{Figure captions:}

Fig.1 Anomalous precipitation (JJAS) over the Indian Land region $\left(\mathrm{mm} \mathrm{day}^{-1}\right)$. Left Panel is for Flood years composite associated with a) La Nina cases, b) Positive IOD, and c) Independent of IOD and La Nina. Right Panel shows composite of Drought years for d) ElNino cases e) Negative EQWIN f) and Independent cases

Fig.2 June-September composite of SST anomalies $\left({ }^{\circ} \mathrm{C}\right.$, shaded) and $850 \mathrm{hPa}$ winds (vector, $\mathrm{m} \mathrm{s}^{-1}$ ). Left Panel is for Flood years composite for a) La Nina cases, b) Positive IOD, and c) Independent of IOD and La Nina. Right Panel shows composite of Drought years for d) ElNino cases e) Negative EQWIN and f) Independent cases

Fig. 3 June-September composite of SLP anomalies (hPa, shaded) and 0.2101 (sigma level) Velocity Potential (contours, $\mathrm{m} * \mathrm{~m} / \mathrm{s}$ ). Left Panel is for Flood years composite for a) La Nina cases, b) Positive IOD, and c) Independent of IOD and La Nina. Right Panel shows composite of Drought years for d) El-Nino cases e) Negative EQWIN and f) Independent cases

Fig. 4 Dominant terms in moisture budget for JJAS period for Flood Cases co-occurred with La Nina: a) MADV (vertically integrated horizontal moisture advection, $\mathrm{W} \mathrm{m}^{-2)}$ b) MDIV (vertically integrated moisture divergence, $\mathrm{W} \mathrm{m}^{-2}$, positive values for divergence and negative for convergence); c) EVAP, evaporation and d) MSE (moist static energy, $\mathrm{W} \mathrm{m}^{-2}$ ). (e)-(h) and (i)-(l) are the same as (a-d), but for flood years with positive IOD and independent cases respectively. Units are $\mathrm{W} \mathrm{m}^{-2}$ with different scales in each panel

Fig. 5 Dominant terms in moisture budget for JJAS period for drought Cases co-occurred with El Nino: a) MADV (vertically integrated horizontal moisture advection, $\mathrm{W} \mathrm{m}^{-2}$ b) MDIV (vertically integrated moisture divergence, $\mathrm{W} \mathrm{m}^{-2}$, positive values for divergence and negative for convergence); c) EVAP, evaporation and d) MSE (moist static energy, $\mathrm{W} \mathrm{m}^{-2}$ ). (e)-(h) and (i)-(l) are the same as (a-d), but for drought years with Negative EQWIN and independent cases respectively. Units are $\mathrm{W} \mathrm{m}^{-2}$ with different scales in each panel

Fig. 6 Dominant terms of the moisture advection averaged for JJAS for Flood Cases associated with La Nina: (a) Anomalous winds acting on climatological moisture gradient (b) Climatological wind acting on anomalous moisture gradient and (c) anomalous wind acting on anomalous moisture gradient. (d)-(f) and (g)-(i) are the same as (a)-(c), but for flood years with positive IOD and independent cases respectively. Units are $\mathrm{W} \mathrm{m}^{-2}$ with different scales in each panel 
438 Fig. 7 Dominant terms of the moisture advection averaged for JJAS for Drought Cases 439 associated with El Nino: (a) Anomalous winds acting on climatological moisture gradient

440 (b) Climatological wind acting on anomalous moisture gradient and (c) anomalous wind 441 acting on anomalous moisture gradient. (d)-(f) and (g)-(i) are the same as (a)-(c), Negative 442 EQWIN and independent cases respectively. Units are $\mathrm{W} \mathrm{m}^{-2}$ with different scales in each 443 panel

\section{Tables:}

445 Table 1 All India Summer Monsoon Rainfall anomaly (land points) for extreme years 446 (Flood/Drought) in order of increasing intensity/severity. The abbreviation in bracket 447 indicates the association of these extreme years with ENSO, IOD, EQWIN or independent 
Figures

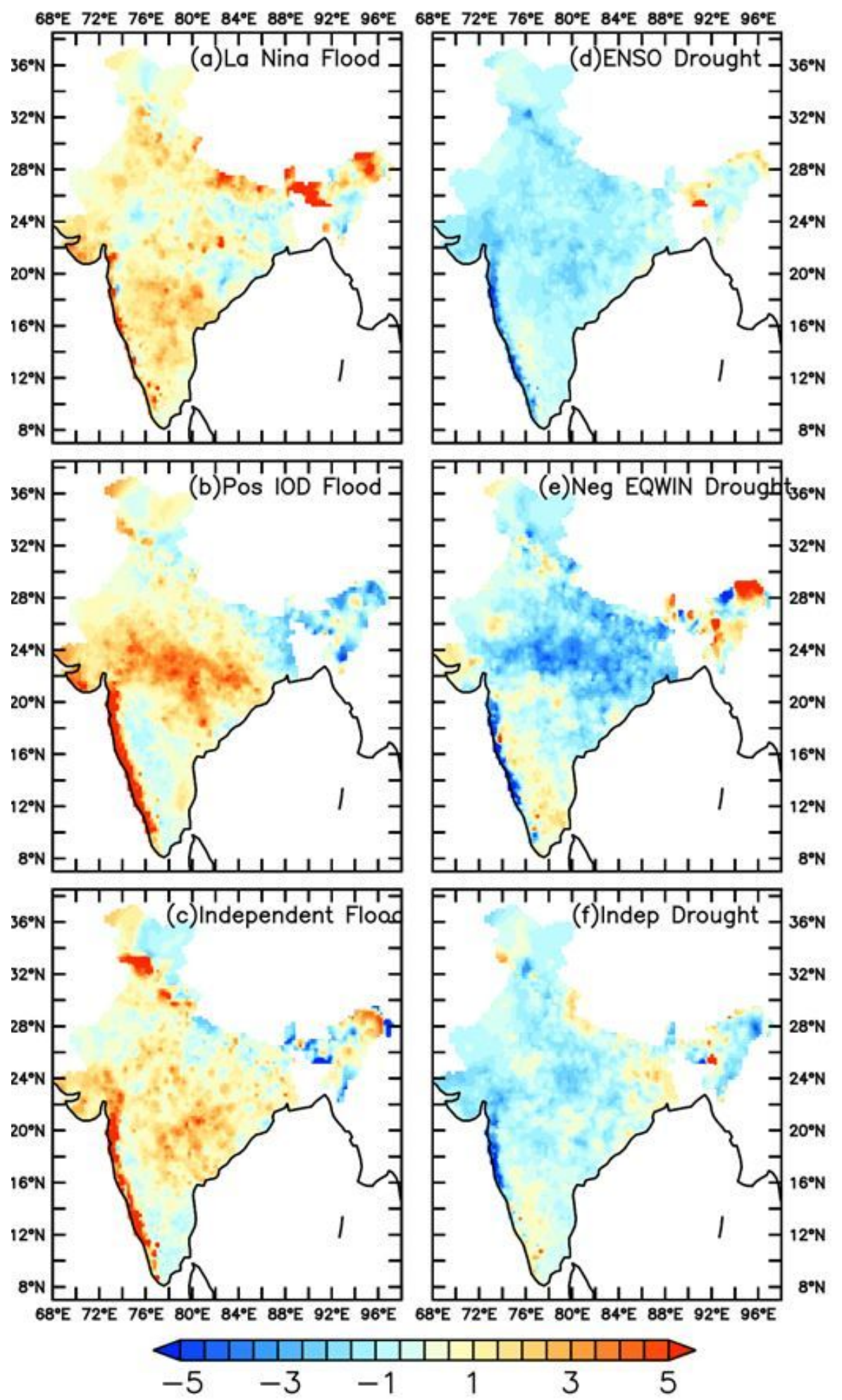

Figure 1

Anomalous precipitation (JJAS) over the Indian Land region (mm day-1). Left Panel is for Flood years composite associated with a) La Nina cases, b) Positive IOD, and c) Independent of IOD and La Nina. 
Right Panel shows composite of Drought years for d) El-Nino cases e) Negative EQWIN f) and Independent cases

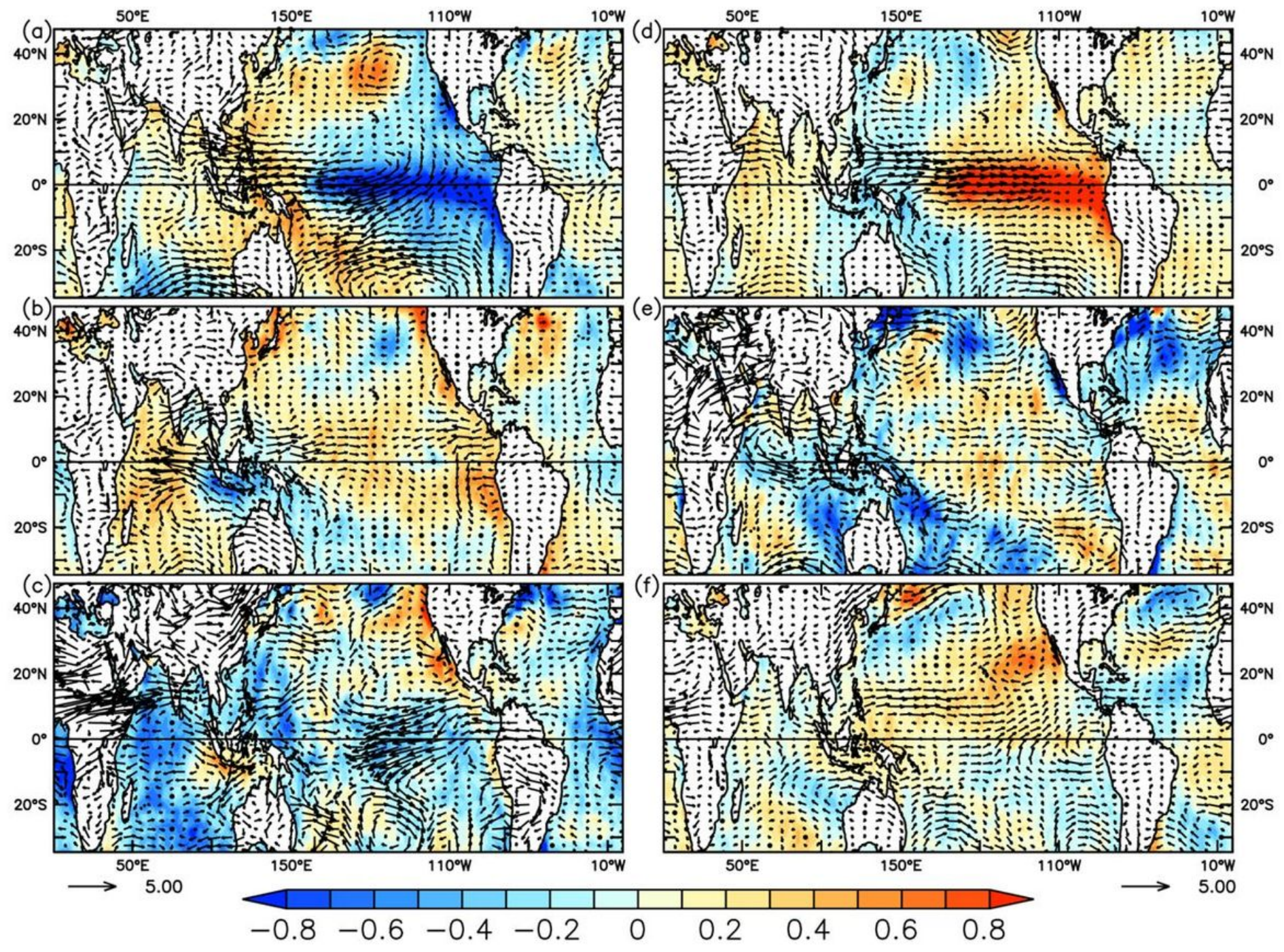

Figure 2

June-September composite of SST anomalies ( ${ }^{\circ} \mathrm{C}$, shaded) and $850 \mathrm{hPa}$ winds (vector, $\mathrm{m} \mathrm{s}-1$ ). Left Panel is for Flood years composite for a) La Nina cases, b) Positive IOD, and c) Independent of IOD and La Nina. Right Panel shows composite of Drought years for d) El-Nino cases e) Negative EQWIN and f) Independent cases 


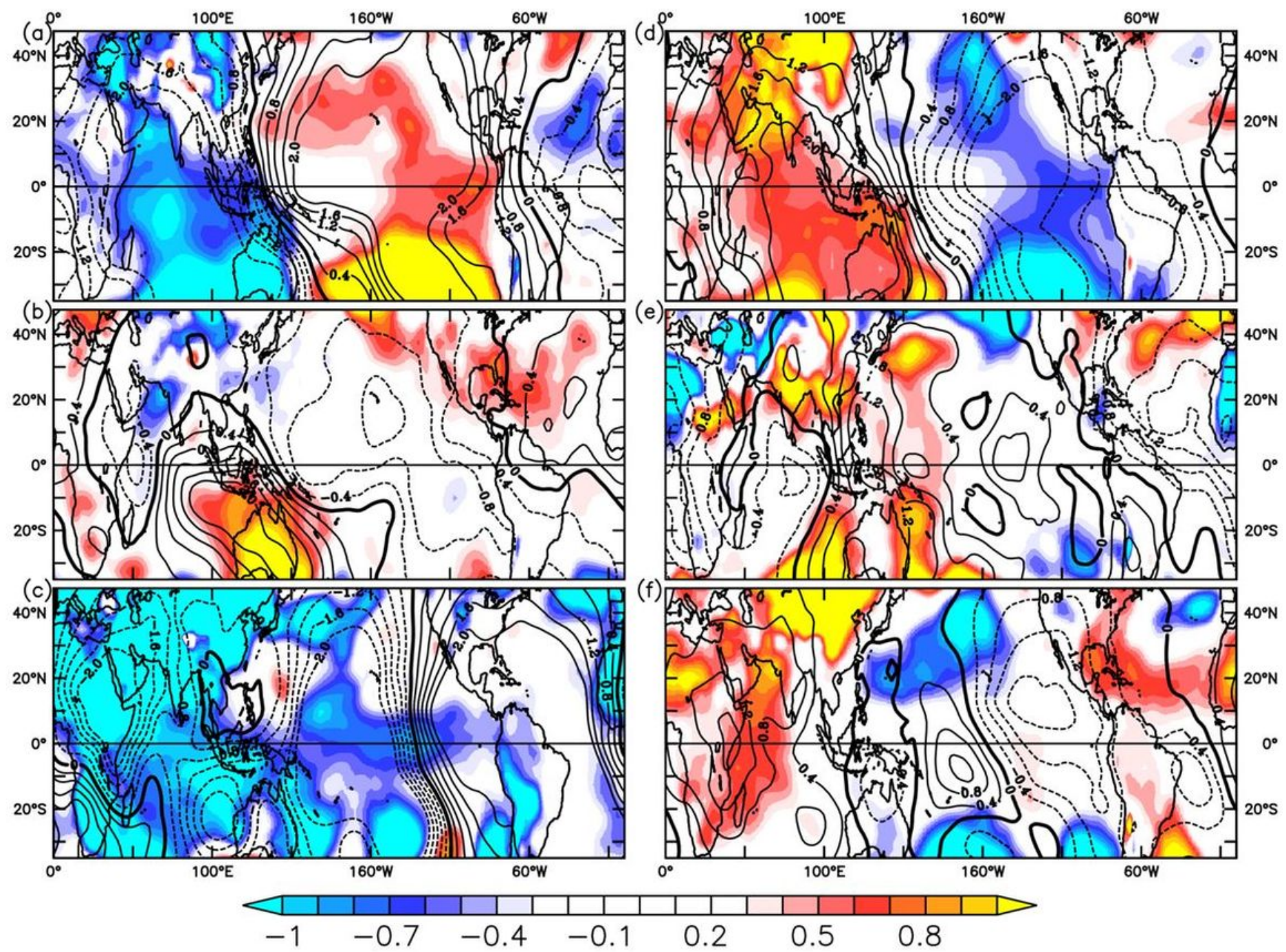

Figure 3

June-September composite of SLP anomalies (hPa, shaded) and 0.2101 (sigma level) Velocity Potential (contours, $m \star m / s$ ). Left Panel is for Flood years composite for a) La Nina cases, b) Positive IOD, and c) Independent of IOD and La Nina. Right Panel shows composite of Drought years for d) El-Nino cases e) Negative EQWIN and f) Independent cases 

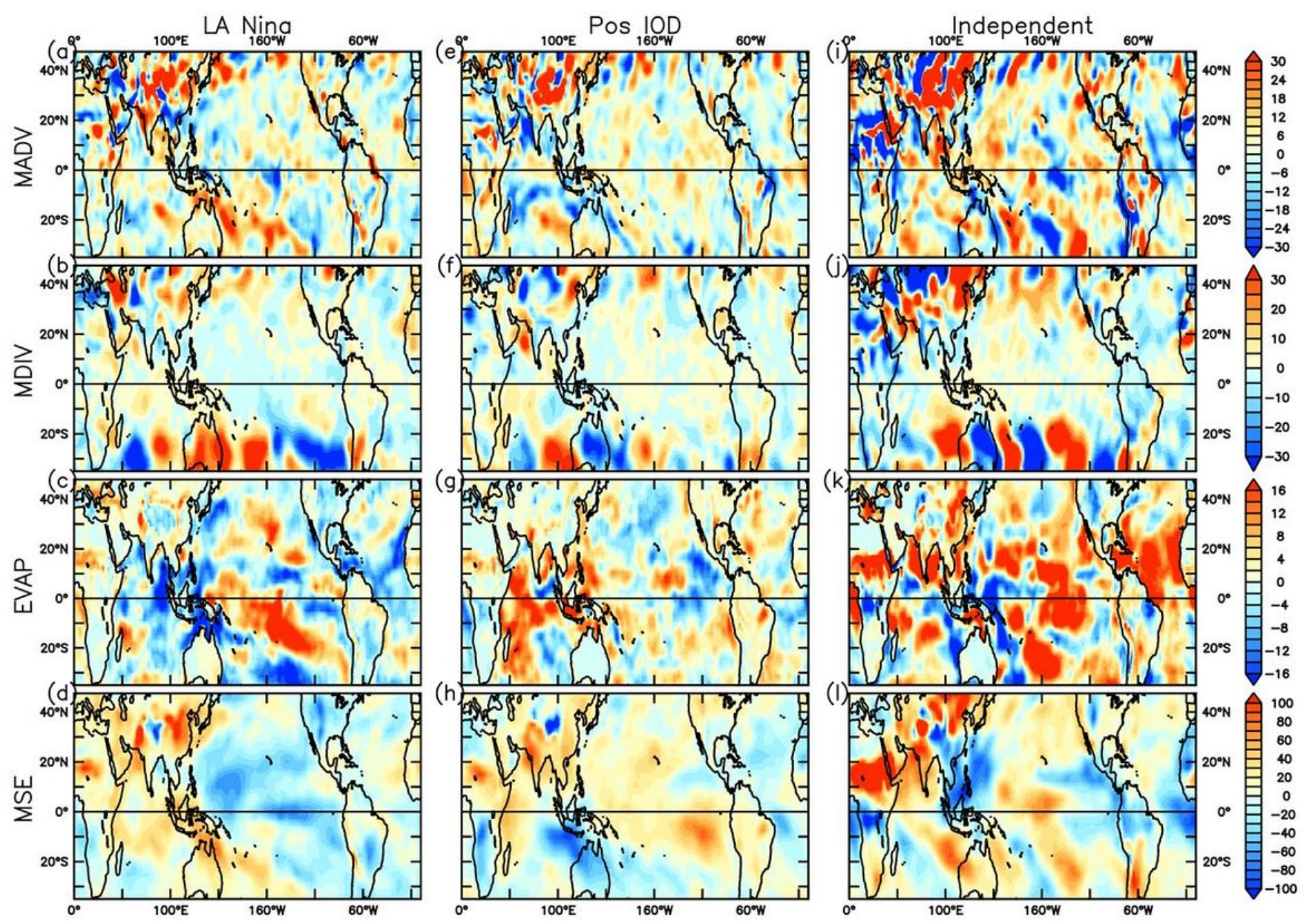

Figure 4

Dominant terms in moisture budget for JJAS period for Flood Cases co-occurred with La Nina: a) MADV (vertically integrated horizontal moisture advection, $\mathrm{W} \mathrm{m-2)} \mathrm{b)} \mathrm{MDIV} \mathrm{(vertically} \mathrm{integrated} \mathrm{moisture}$ divergence, $\mathrm{W} \mathrm{m}-2$, positive values for divergence and negative for convergence); c) EVAP, evaporation and d) MSE (moist static energy, W m-2). (e)-(h) and (i)-(l) are the same as (a-d), but for flood years with positive IOD and independent cases respectively. Units are $\mathrm{W} \mathrm{m}-2$ with different scales in each panel 

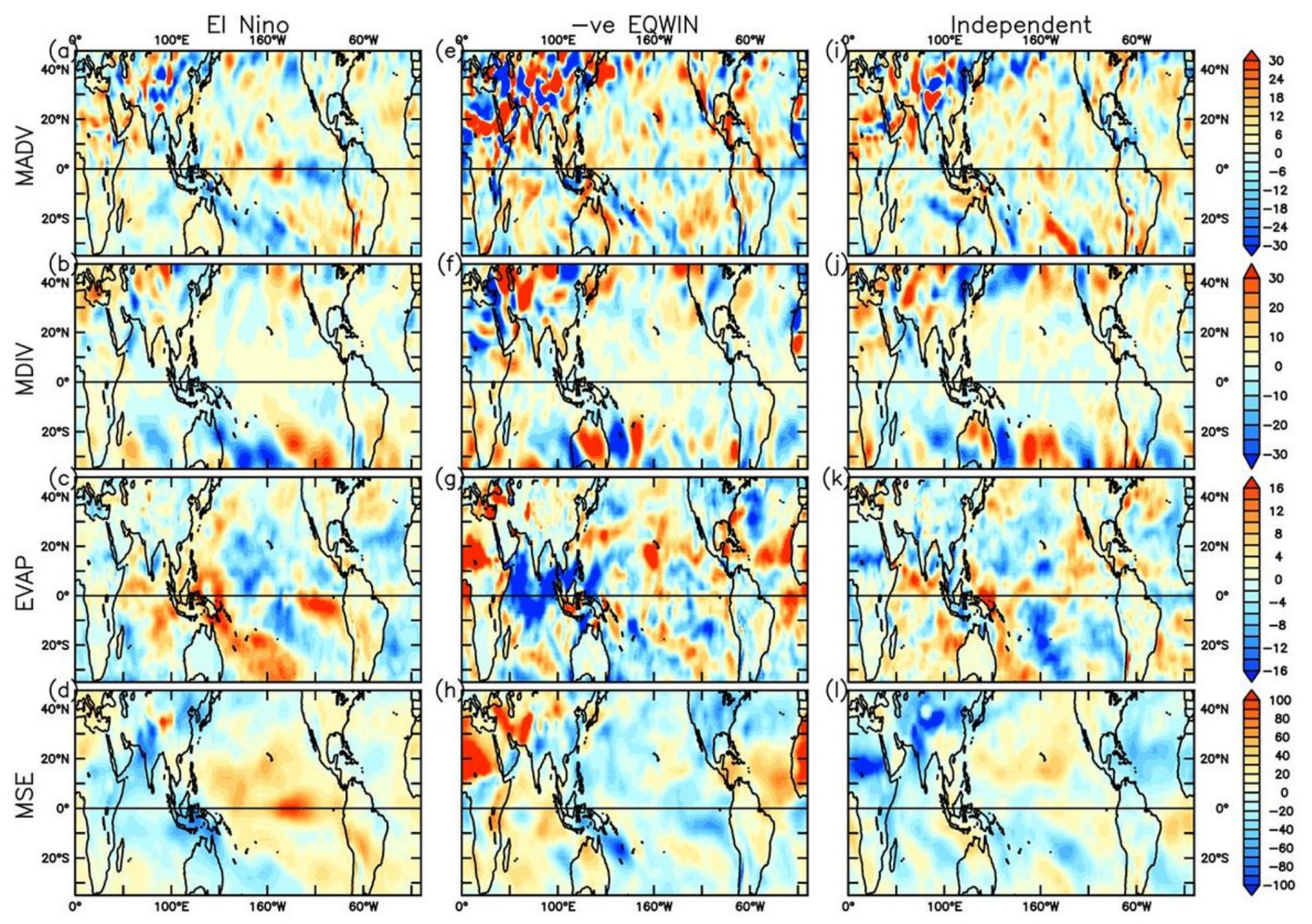

Figure 5

Dominant terms in moisture budget for JJAS period for drought Cases co-occurred with El Nino: a) MADV (vertically integrated horizontal moisture advection, $\mathrm{W} \mathrm{m-2)} \mathrm{b)} \mathrm{MDIV} \mathrm{(vertically} \mathrm{integrated} \mathrm{moisture}$ divergence, $\mathrm{W} \mathrm{m}-2$, positive values for divergence and negative for convergence); c) EVAP, evaporation and d) MSE (moist static energy, $\mathrm{W} \mathrm{m-2)}$. (e)-(h) and (i)-(l) are the same as (a-d), but for drought years with Negative EQWIN and independent cases respectively. Units are W m-2 with different scales in each panel 

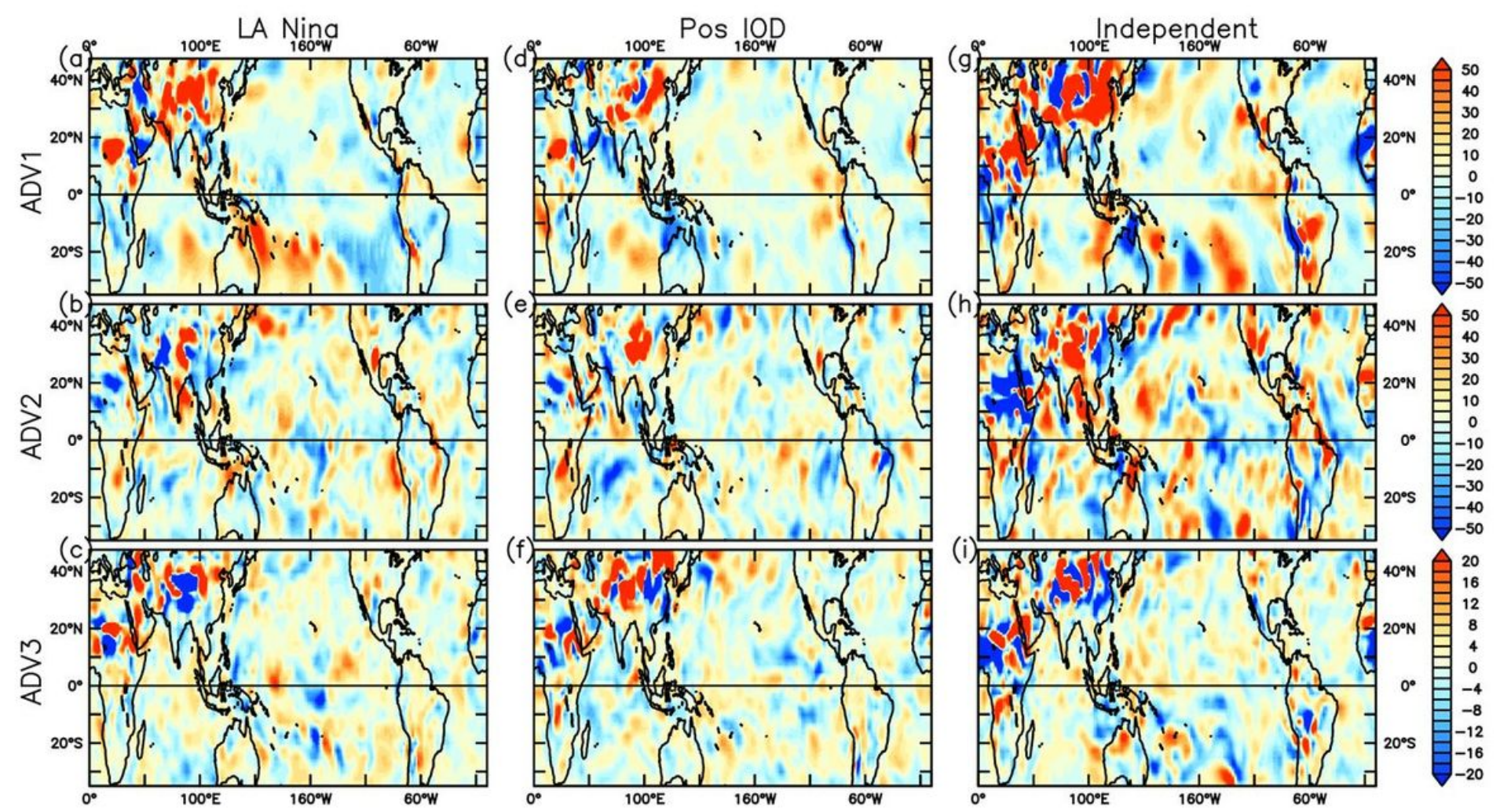

Figure 6

Dominant terms of the moisture advection averaged for JJAS for Flood Cases associated with La Nina: (a) Anomalous winds acting on climatological moisture gradient (b) Climatological wind acting on anomalous moisture gradient and (c) anomalous wind acting on anomalous moisture gradient. (d)-(f) and (g)-(i) are the same as (a)-(c), but for flood years with positive IOD and independent cases respectively. Units are $\mathrm{W} \mathrm{m-2}$ with different scales in each panel 

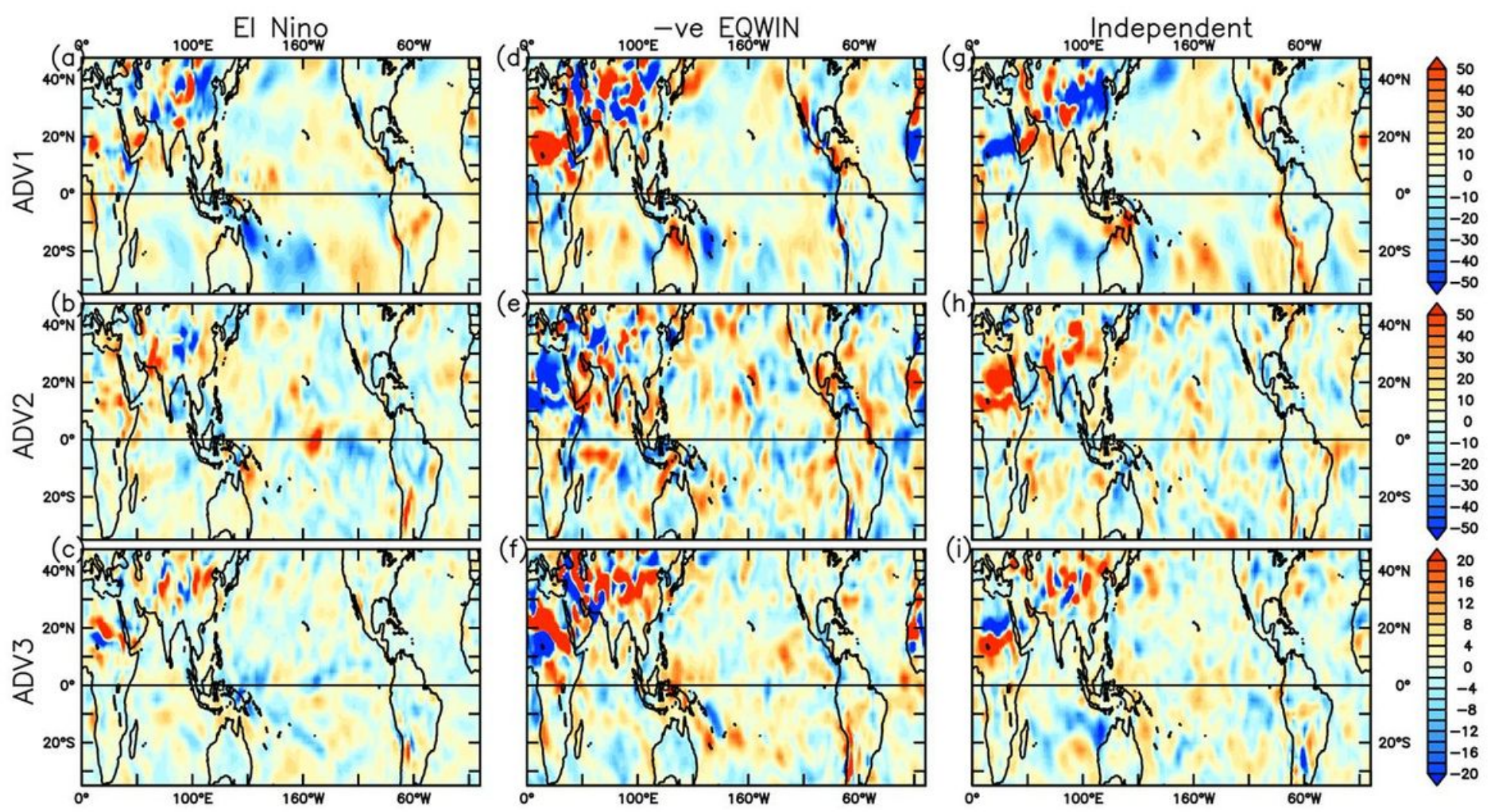

Figure 7

Dominant terms of the moisture advection averaged for JJAS for Drought Cases associated with El Nino: (a) Anomalous winds acting on climatological moisture gradient (b) Climatological wind acting on anomalous moisture gradient and (c) anomalous wind acting on anomalous moisture gradient. (d)-(f) and (g)-(i) are the same as (a)-(c), Negative EQWIN and independent cases respectively. Units are W m-2 with different scales in each panel 